Acquisition and extinction of an

\section{instrumental response as a function \\ of delay of intracranial stimulation \\ reward and amount of training '}

SHELTON E. HENDRICKS ${ }^{2}$ and ARNOLD A. GERALL, Tulane University, New Orleans, La. 70118

Rats were trained to barpress for intracranially delivered electrical stimulation under conditions of 0.0-, 0.5-, and 1.0-sec delay of reward before initiating extinction trials. One group received 3 , and another 10 , training days with each delay interval. Both delay of reward and amount of training influenced acquisition performance, but neither affected extinction rate. Results are discussed in terms of a hypothesis implicating mediating responses as the critical factor determining extinction rates in the ICR situation.

Instrumental behaviors learned with intracranial reward (ICR) seem to differ from those acquired with more conventional reinforcements in that they are performed at high rates, manifest few signs of satiation, and tend to extinguish rapidly (Olds \& Milner, 1954: Seward, Uyeda, \& Olds, 1959). Two variables distinguishing ICR from other learning are the absence of a delay between the operant response and reward, and the relatively large number of trials provided. Both of these variables increase performance levels during acquisition and decrease responding in extinction. Also, according to Plisk off, Wright, \& Hawkins (1965) and Gibson, Reid, Saki, \& Porter (1965), few mediating responses are acquired in the ICR situation that can sustain responding during extinction. The present study investigated the role of these variables in the acquisition and extinction of responses rewarded with ICR during either 3 or 10 training sessions with three delay intervals.

\section{METHOD}

Twelve Sprague-Dawley male rats that barpressed for ICR were used as Ss. Platinum electrodes were implanted under nembutal sodium and chlorohydrate anesthesia in the medial forebrain bundle; deGroot coordinates $4.2 \mathrm{~mm}$ anterior to and $3.2 \mathrm{~mm}$ below the interaural line and $1.2 \mathrm{~mm}$ lateral to the midline. Training and extinction were conducted in $12 \times 12 \times 10$ in. Skinner boxes. Fisher connecting leads and swivels were used to connect the implanted electrodes to the stimulating voltage that was derived from a 110-V 10-cycles/sec constant regulated source that was stepped down by a transformer to $6.3 \mathrm{~V}$. This voltage was further controlled by a $20 \mathrm{kohm} 10$-turn variable potentiometer.

Ss could press freely and receive a maximum of $0.5 \mathrm{sec}$ of stimulation for each press. If the bar was released before $0.5 \mathrm{sec}$, intracranial stimulation (ICS) ceased and another press was required to initiate it again. Ss were required to hold the bar down for a specified time if the pulse-delivering circuit was to be activated. Release of the bar caused the timer to reset. Counters were arranged in the circuit so that pressing the bar for an instant caused one set of counters to operate, while another was triggered only after it had been held for the required delay interval.

Both groups of six Ss received three training treatments, each followed by 3 days of extinction under conditions of $0.0-, 0.5-$, and 1.0-sec delay of reward. Six sequences representing the six permutations of order of presentation of the three delay conditions were used. One group received 3 and the other group received 10 daily training sessions under each delay condition. During training sessions, Ss were allowed to barpress until they had received 1,000 rewards. The time required to emit 1,000 rewards was recorded during each session. Also, number of responses emitted, both rewarded and unrewarded, and amperage levels were recorded every $10 \mathrm{~min}$.

Extinction was introduced the day following completion of a block of training sessions. On this day, electrical stimulation was available for the first $10 \mathrm{~min}$ and cumulative responses were recorded every minute for $30 \mathrm{~min}$. On the following 2 days, Ss were placed in the box with the current turned off and again cumulative responses were recorded. At the conclusion of the experiment, Ss were sacrificed and electrode position histologically verified.

\section{RESULTS}

The basic measure of acquisition behavior was the time required by $S$ to obtain 1,000 rewards. As the presence of a delay interval of necessity produced differences between delay conditions, a correction factor calculated from the total time imposed by 1,000 delays of 0.5 and 1.0 sec was subtracted from the appropriate raw scores. Analysis of variance performed with these corrected scores revealed that level of training, position in the training sequence, and delay were statistically significant factors $(p<.05)$. Duncan's multiple range test showed that acquisition time with the 1.0-sec delay was significantly different from the $0.0-$ and 0.5 -sec delay conditions, and the latter two were not significantly different from each other. Figures 1 and 2 show the acquisition performance for those Ss receiving 3 and 10 days of training, respectively, under each delay condition.

Analysis of the extinction data indicated that the various delays of reward and amount of training used in this study produced no statistically significant differential effects on extinction performance. Analyses of variance performed at many points in the extinction process yielded no significant differences. Extinction performance, when measured as a percent of acquisition performance, also failed to yield reliable differences associated with acquisition treatments. Response rates during the first $10 \mathrm{~min}$ of extinction following the first training treatment are shown as a function of delay of reward in Fig. 3.

One difference that did appear was in the extinction data variance. The standard deviations of the 0.5 - and 1.0-sec delay conditions were approximately eight times larger than that obtained with $0.0-$ sec delay (0.0-sec delay, 5.3; 0.5-sec, 45.1; 1.0-sec, 37.1). This difference is present only following the first training treatment. All standard deviations are large following the second and third training sessions. Thus, those Ss with no delay of ICR and having

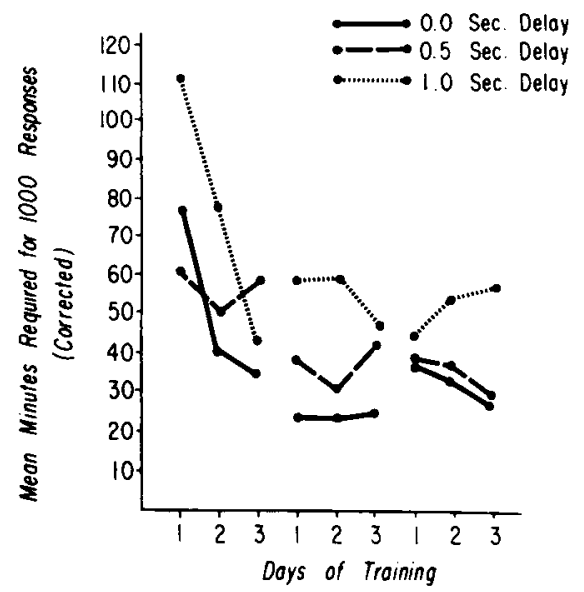

Fig. 1. Mean corrected minutes required by Ss receiving 3 days of training to emit 1,000 responses under three delay conditions. 


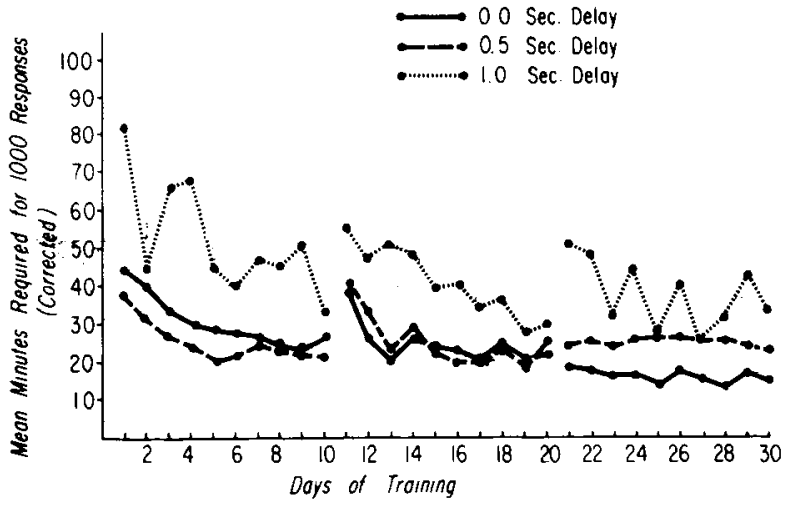

had no previous training or extinction experience show considerably less variable extinction performance than those having delayed ICR and those having had training and extinction treatment.

Correlational analysis revealed no relationship between the number of nonrewarded "abortive" responses and either acquisition or extinction performance. Histological examination revealed that all electrode tips were in the medial forebrain bundle.

\section{DISCUSSION}

The effects of delay of ICR upon acquisition performance in this study were similar to those reported by Keesey

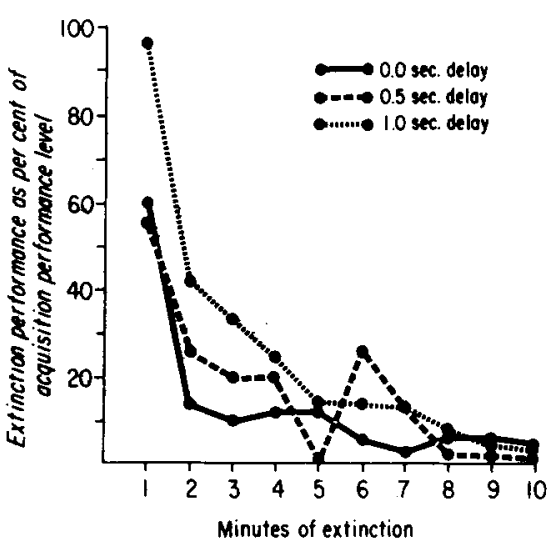

Fig. 3. Extinction after training under the three delay-of-reward intervals.
(1964), who found that delay of ICR retarded performance in a manner comparable to that found with food reward. Differences in amount of training upon acquisition performance were consistent with the generality of improved performance with practice.

Contrary to the acquisition results. neither delay of reward nor amount of training had significant differential effects upon extinction performance. It is possible that the 3,000 trials employed as the lower training level was beyond the point at which different amounts of training would produce varying degrees of extinction. Observation of acquisition behavior indicated that some Ss tended to barpress in stereotypical manners. These seemingly noninstrumental responses might be necessary for the mediation of the delay interval. If resistance to extinction is a function of the extent to which intervening responses are established, as proposed by Pliskoff et al (1965) and Gibson et al (1965), it might be hypothesized that Ss developing intervening responses were the ones that showed greater resistance to extinction. The increased variability in extinction performance may have been due to varying extents to which consistent intervening responses were established as part of the S's response mode. However, even the largest number of extinction responses observed in the present study were not comparable to the amount of extinction responding reported by Deutsch
Fig. 2. Mean corrected minutes required by Ss receiving 10 days of training to emit $\mathbf{1 , 0 0 0}$ responses under three delay conditions.

\& DiCara (1967) for food-deprived rats trained with ICR. These data suggest that an empty delay or one in which mediating responses occur. while having a small effect on behavior during extinction. does not account for the considerable differences manifested between instrumental responses exhibited by the satiated rat in the ICR condition and the rat having had food reward.

\section{RII ERI:NCES}

De GROOT. J. The rat forebrain in stereotaxic coordinates. Ansterdam: Noord-Hollandsche Liituevers. 1959.

DLLISCH. 1. 1. \& Dic IRI. L., Hunger and extinction in indratianial self-stmulation.

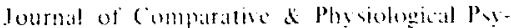
cholones. 1967, 63. 34t-3+7

GIBSON. W. W.. RFID. L. D. SAKI. M.. \& PORTIR. P. B. Intracranial reinforement compared with sugar-water reinforcement. Science, $1965,148,1357-1359$.

KEFSF Y, R. F. Intracranial rew ard delay and the acquisition rate of a brightness discrimination. Science. 1964. 143. 700-702.

OLDS. J. Sclf-stimulation of the brain: Its use to study the local effects of hunger. sex and drugs. Science. 127, 315-324.

OLDS. J.. \& MILNER, P. Positive reinforcement produced by electrical stimulation of the septal area and other regions of the rat brain. Journal of Comparative \& Physiological Psychology, 1954, 47, 419-427.

PLISKOF $\mathrm{F}$, S. S., WRIGHT, J. E., \& HAWKINS. $F$ D. Brain stimulation as a reinforcer: Intermittent schedules. Joumal of the Experimental Analysis of Behavior, 1965, 8, 75-88.

SEWARD, J. P., UYFDA, A., \& OLDS, J. Resistance to extinction following intracranial self-stimulation. Journal of Comparative \& Physiological Psychology, 1959, 52. 294-299. NOTES

1. This study is based on a thesis by the first author submitted to the Graduate School of Tulane University in partial filfillment of the requirements for the MS degrec. The study was supported in part by Research Grant HD 00867 from the National Institute of Child Health and Human Development.

2. Requests for reprints should be sent to Shelton E. Hendricks, who is now at the Department of Psychology. University of Nebraska at Omaha. Omaha. Nebr. 68101 . 